\title{
Seasonal Changes in the Relationship between Serum Concentration of $\beta$-Cryptoxanthin and Serum Lipid Levels
}

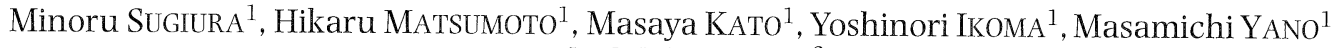 \\ and Akihiko NAGAO ${ }^{2}$ \\ ${ }^{1}$ Department of Citrus Research, National Institute of Fruit Tree Science, Shizuoka 424-0292, Japan \\ ${ }^{2}$ Food Materials Research Division, National Food Research Institute, Tsukuba 305-8642, Japan
}

(Received May 13, 2004)

\begin{abstract}
Summary Beta-cryptoxanthin ( $\beta$-CRX) is a carotenoid pigment found especially in Satsuma mandarin (Citrus unshiu Marc.) fruit, which is mainly produced in Japan. Previously, we found that serum $\beta$-CRX concentrations rose to extreme levels as the frequency of consumption of Satsuma mandarin increases. Using 94 non-smoking female volunteers, the present study evaluated the relationship between serum concentration of $\beta$-CRX and serum lipid levels in September, when the Satsuma mandarin is not in season, and in January of the next year, when it is in season. The mean of increment in serum $\beta$-CRX concentrations from September to January was $95.9 \pm 84.0 \mu \mathrm{g} / \mathrm{dl}$ (mean \pm SD). Although the changes in serum lipid levels did not correlate with the changes in serum $\beta$-CRX, the serum HDL-cholesterol and apo-lipoprotein $A_{1}$ levels in the highest quartile of the increment in serum $\beta$ CRX from September to January were significantly higher than those in the lowest quartile in both September and January. In cross-sectional analyses, serum $\beta$-CRX concentrations were correlated positively with those of LDL-cholesterol and apo-lipoprotein B levels in September, but these correlations were not observed in January. In contrast, serum $\beta$-CRX concentrations were correlated positively with those of HDL-cholesterol and apo-lipoprotein $A_{1}$ levels in January. These results suggest that habitual eating of Satsuma mandarin while it is in season may influence lipid metabolism throughout the year.
\end{abstract}

Key Words $\beta$-cryptoxanthin, Satsuma mandarin, seasonal change, serum lipid

Recent epidemiological studies and animal experiments provide strong support for the hypothesis that the daily consumption of fruits and vegetables may be effective in the prevention of diseases such as cancer, coronary heart disease, diabetes, and hypercholesterolemia (1-5). Previously, we discovered that the serum concentration of $\beta$-cryptoxanthin $(\beta$-CRX), which is abundant in Satsuma mandarin, increased in proportion to the consumption of Satsuma mandarin and was a useful biomarker for estimating the frequency of Satsuma mandarin consumption $(6,7)$. These findings make it possible to evaluate the beneficial effect of Satsuma mandarin by measuring the serum $\beta$-CRX level as a useful biomarker that nearly reflects the frequency of Satsuma mandarin consumption.

In this study, we evaluated the relationship between Satsuma mandarin consumption and lipid metabolism by measuring serum $\beta$-CRX levels in September, when the Satsuma mandarin is not in season, and in January of the next year, when it is in season. Seasonal changes in the relationship between the serum $\beta$-CRX concentrations and lipid metabolism were discussed.

\section{SUBJECTS AND METHODS}

A total of 94 non-smoking females, from 41 to $69 \mathrm{y}$

E-mail: msugiura@affrc.go.jp of age (median, $56 \mathrm{y}$; SD, 6.81), who were rural residents of Shizuoka Prefecture, Japan, volunteered for the study. All of the subjects were classified to be healthy according to their answers in a self-administered questionnaire. All study subjects gave their written informed consent before the study. The subjects lived at home, and they consumed their usual diets. None of the subjects took medications, vitamins, or mineral supplements. A self-administered questionnaire was used to collect information about the consumption frequency of Satsuma mandarin and other fruits and vegetables for $1 \mathrm{wk}$ before a blood test. Specific attention was given to the consumption of fruits and vegetables that contain $\beta$-CRX, such as apricot, chili, loquat, orange, peach, pepper, papaya, and related processed foods, including juice or canned foods, in the light of previous reports concerning carotenoid contents in foods $(8-11)$.

Blood samples were obtained in the morning after the subjects had fasted overnight. Blood sampling was performed twice-once in September, when the Satsuma mandarin is not in season, and once in January of the next year, when it is in season. The serum total cholesterol, triacylglycerols, HDL cholesterol, and LDL cholesterol of each individual were measured by enzymatic photometric methods using commercial kits (KyowaMedics, Inc., Tokyo, Japan). Apo-lipoprotein $\mathrm{A}_{1}$ and $\mathrm{B}$ levels were measured by TIA methods using commer- 
cial kits (Nittoh-bouseki, Inc., Tokyo, Japan). Serum samples were stored at $-80^{\circ} \mathrm{C}$ until $\beta$-CRX analysis. The concentrations of serum carotenoids, lutein, lycopene, $\alpha$-carotene, $\beta$-carotene, $\beta$-cryptoxanthin, and zeaxanthin were analyzed by reverse-phase high-performance liquid chromatography (HPLC) using $\beta$-apo8 -carotenal as an internal standard. Serum samples were mixed with $\mathrm{H}_{2} \mathrm{O}$ and ethanol containing $\beta$-apo- $8^{\prime}$ carotenal and extracted into hexane. The organic layer was removed, evaporated to dryness at room temperature, resolved in chloroform:ethanol (1:19), and transferred to a microvial for automatic injection. The HPLC system was Model HP-1100 (Hewlett-Packard, Toronto, Canada) fitted with a $201 \mathrm{TP} 54$ reverse-phase $\mathrm{C} 18 \mathrm{col}$ umn (Grace/Vydac, CA, USA). Six carotenoids were monitored at $480 \mathrm{~nm}$ in the HPLC system. The mobile phase component was methanol:tetrahydrofuran: $\mathrm{H}_{2} \mathrm{O}$ (94:5:1), and the flow rate of the phase was $0.8 \mathrm{~mL} /$ min. The peaks of the six carotenoids were identified by the retention time and quantified using standard curves of authentic lutein, lycopene, $\alpha$-carotene, $\beta$-carotene, $\beta$-cryptoxanthin, and zeaxanthin (Funakoshi, Tokyo, Japan).

The statistical analyses were performed using the SPSS 12.0J for Windows (SPSS Japan, Inc., Tokyo). Study subjects were categorized into four groups, according to the quartile level of the changes in serum $\beta$-CRX concentrations from September to January: 1st (lowest) to 4 th (highest). The mean, standard deviation (SD), and median of Satsuma mandarin consumption, age, body mass index, serum $\beta$-CRX, and serum lipid levels in each of the 4 quartiles were calculated, and all data were represented as means \pm SD. Pearson correlation coefficients between serum $\beta$-CRX and serum lipid levels were evaluated. Partial correlation coefficients were examined after adjustment for age and BMI. Significance was accepted if the null hypothesis was rejected at the $p<0.05$ level.

This study was approved by the ethics committee of the National Institute of Fruit Tree Science.

\section{RESULTS AND DISCUSSION}

The change in serum $\beta$-CRX in all subjects from September to January was $95.9 \pm 84.0 \mu \mathrm{g} / \mathrm{dL}$ (mean $\pm \mathrm{SD}$ ). Study subjects were categorized into four groups, according to the quartile level of the changes in serum $\beta$-CRX from September to January. Table 1 is a summary of Satsuma mandarin consumption, age, body mass index, serum $\beta$-CRX, and serum lipid levels in relation to the quartile level of the changes in serum $\beta$ CRX concentrations. In January, when Satsuma mandarin is in season, the level of serum $\beta$-CRX was much higher than that in September, when Satsuma mandarin is not in season (Table 1). Except for Satsuma mandarin, the frequency of consumption of fruits and vegetables and related processed food, including juice or canned foods that contain $\beta$-CRX, was not statistically different in the 4 quartiles in January (data not shown). Furthermore, in September, none of the subjects ate fruits and vegetables and related processed food that contains $\beta$-CRX for at least 2 mo (data not shown). From these results, we assumed that the increment of serum $\beta$-CRX was due to the increase in the consumption of Satsuma mandarin.

In our survey, the serum concentration of $\beta$-CRX in those who had consumed significant quantities of Satsuma mandarin was much higher than that reported in previous other reports $(12,13)$. These studies reported that the values of serum $\beta$-CRX levels were about $20 \mu \mathrm{g} / \mathrm{dL}$ or less. Although apricot, chili, loquat, papaya, peach, pepper, and tangerine contain $\beta$-CRX $(8-11)$, they are not as large a source of $\beta$-CRX as Satsuma mandarin, according to our survey. Actually, in this survey, the frequency of consumption of these foods was much lower than that of Satsuma mandarin and did not differ in the 4 quartiles (data not shown). One Satsuma mandarin (about $100 \mathrm{~g}$ ) includes $1-2 \mathrm{mg}$ of $\beta$ CRX in juice sacs, and none of the fruits or vegetables in this study contained $\beta$-CRX in such large quantities $(10,11)$. We estimated that the daily intake of $\beta$-CRX in participants who ate one to three Satsuma mandarins daily was about 1 to $6 \mathrm{mg}$ or more. Because of this large $\beta$-CRX intake from Satsuma mandarin, the serum $\beta$ CRX level was much higher in the present study than in others. It is possible that serum $\beta$-CRX is a useful biomarker in epidemiological study to evaluate the beneficial effects of Satsuma mandarin if the survey is conducted in an area where residents eat a large quantity of Satsuma mandarin compared with the rest of Japan.

In this study, the seasonal changes in the relationship between serum lipid levels and Satsuma mandarin consumption were evaluated by measuring the serum $\beta$ CRX level. As shown in Table 1, age, body mass index, serum total-cholesterol, triacylglycerols, LDL-cholesterol, and apo-lipoprotein B levels were not different in the 4 quartiles in either September or January. In contrast, serum HDL-cholesterol and apo-lipoprotein $A_{1}$ levels in the highest quartile were significantly higher than those in the lowest quartile in both September and January. However, the changes in these serum lipid levels did not correlate with the change in serum $\beta$-CRX concentration (Table 1). On the other hand, positive correlations between the changes in serum $\beta$-CRX with HDL-cholesterol and apo-lipoprotein $A_{1}$ levels were observed in both September and January (Table 2). After adjusting for age and BMI, a partial correlation coefficient between the changes in $\beta$-CRX with HDLcholesterol levels was statistically significant. We also analyzed the serum concentrations of five other carotenoids: i.e., lutein, zeaxanthin, lycopene, $\alpha$-carotene, and $\beta$-carotene; however, the serum concentrations of these carotenoids were not statistically different in the 4 quartiles of the changes in serum $\beta$-CRX in September and January (data not shown). Furthermore, no statistically significant correlations between the changes in these carotenoids and serum lipid levels were observed (Table 3). These results suggest that HDL-cholesterol and apo-lipoprotein $A_{1}$ levels in participants who eat a large quantity of Satsuma mandarin are higher than those in participants who rarely eat any. The habitual 


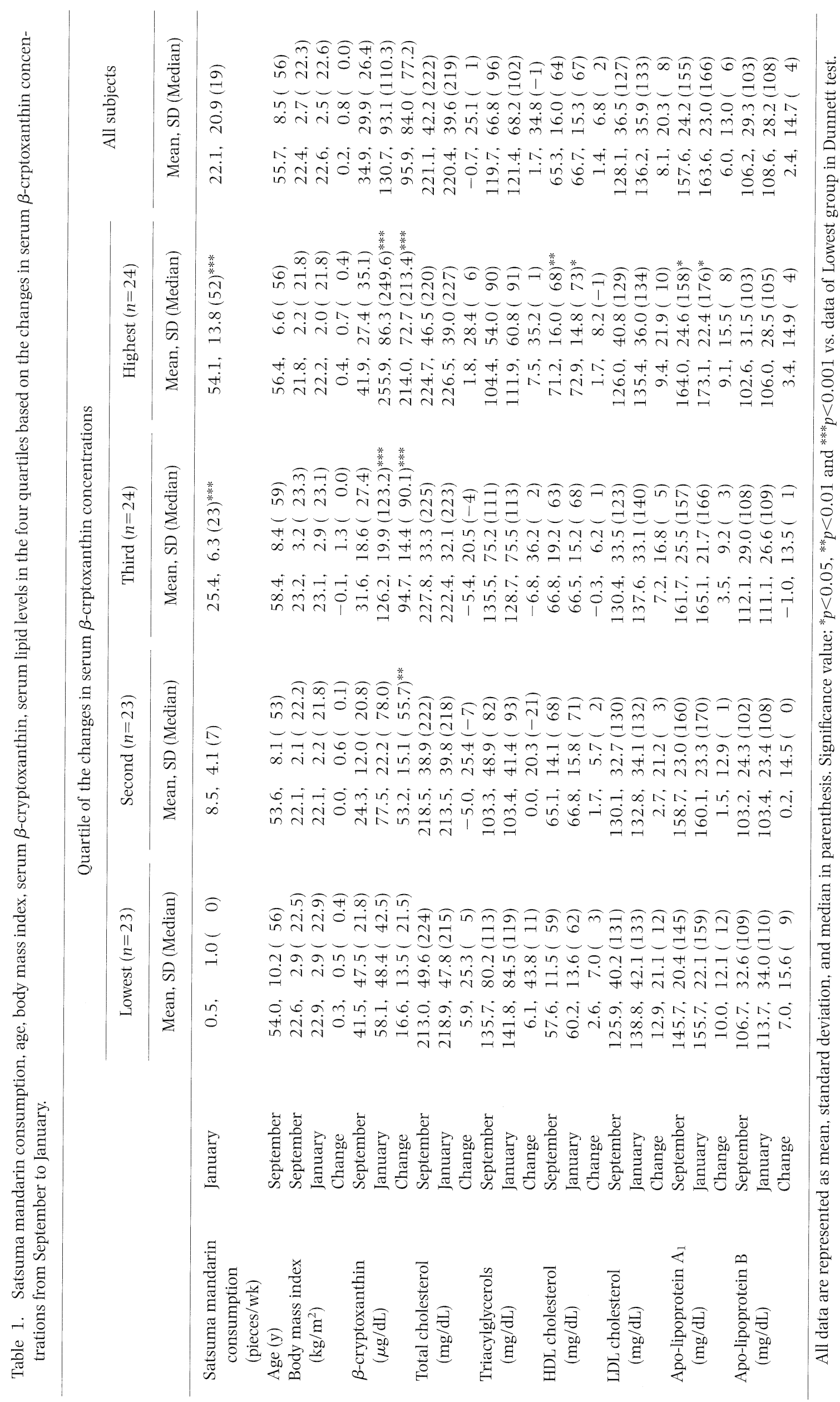


Table 2. Correlation coefficients of serum $\beta$-cryptoxanthin with serum lipid levels.

\begin{tabular}{|c|c|c|c|c|c|}
\hline & & \multicolumn{4}{|c|}{ Serum $\beta$-cryptoxanthin concentrations ( $\mu \mathrm{g} / \mathrm{dL}$ ) } \\
\hline & & \multirow{2}{*}{ September } & \multirow{2}{*}{ January } & \multicolumn{2}{|c|}{ Change } \\
\hline & & & & Crude & Adjusted $^{1}$ \\
\hline \multirow[t]{3}{*}{ Total cholesterol (mg/dL) } & September & $0.351^{* * *}$ & - & 0.095 & 0.098 \\
\hline & January & - & $0.220^{*}$ & 0.095 & 0.076 \\
\hline & Change & - & - & -0.01 & -0.041 \\
\hline \multirow[t]{3}{*}{ Triacylglycerols (mg/dL) } & September & $0.220^{*}$ & - & -0.123 & -0.112 \\
\hline & January & - & 0.02 & -0.053 & -0.055 \\
\hline & Change & - & - & 0.133 & 0.149 \\
\hline \multirow[t]{3}{*}{ HDL cholesterol (mg/dL) } & September & -0.086 & - & $0.248^{*}$ & $0.224^{*}$ \\
\hline & January & - & $0.206^{*}$ & $0.254^{*}$ & $0.235^{*}$ \\
\hline & Change & - & - & -0.013 & -0.021 \\
\hline \multirow[t]{3}{*}{ LDL cholesterol (mg/dL) } & September & $0.331^{* *}$ & - & -0.006 & 0.005 \\
\hline & January & - & 0.113 & -0.02 & -0.03 \\
\hline & Change & - & - & -0.024 & -0.059 \\
\hline \multirow[t]{3}{*}{ Apo-lipoprotein $A_{1}(\mathrm{mg} / \mathrm{dL})$} & September & -0.109 & - & $0.206^{*}$ & 0.176 \\
\hline & January & - & $0.238^{*}$ & $0.275^{* *}$ & $0.245^{*}$ \\
\hline & Change & - & - & 0.101 & 0.095 \\
\hline \multirow[t]{3}{*}{ Apo-lipoprotein B (mg/dL) } & September & $0.330^{* *}$ & - & -0.022 & -0.017 \\
\hline & January & - & 0.085 & -0.042 & -0.054 \\
\hline & Change & - & - & -0.037 & -0.066 \\
\hline
\end{tabular}

${ }^{1}$ Partial correlation coefficients of the changes in serum $\beta$-cryptoxanthin concentrations with lipoprotein and apo-lipoprotein levels after adjustment for age and body mass index.

Significance value; ${ }^{*} p<0.05,{ }^{* *} p<0.01$ and ${ }^{* * *} p<0.001$.

Table 3. Pearson correlation coefficients of the change of serum carotenoid concentrations with serum lipid levels.

\begin{tabular}{|c|c|c|c|c|c|c|}
\hline & & \multicolumn{5}{|c|}{ Change of serum carotenoid concentrations $(\mu \mathrm{g} / \mathrm{dL})$} \\
\hline & & Lutein & Lycopene & $\alpha$-Carotene & $\beta$-Carotene & Zexahnthin \\
\hline \multirow[t]{3}{*}{ Total cholesterol (mg/dL) } & September & 0.133 & -0.039 & -0.103 & -0.075 & 0.086 \\
\hline & January & 0.079 & 0.026 & -0.077 & 0.023 & 0.063 \\
\hline & Change & -0.099 & 0.107 & 0.052 & 0.163 & -0.045 \\
\hline \multirow[t]{3}{*}{ Triacylglycerols (mg/dL) } & September & 0.166 & 0.111 & 0.054 & 0.078 & $0.212^{*}$ \\
\hline & January & 0.171 & 0.006 & 0.043 & 0.055 & 0.189 \\
\hline & Change & 0.030 & -0.126 & -0.053 & -0.046 & -0.015 \\
\hline \multirow[t]{3}{*}{ HDL cholesterol (mg/dL) } & September & -0.080 & -0.064 & -0.179 & -0.189 & -0.152 \\
\hline & January & -0.101 & -0.044 & -0.099 & -0.107 & -0.138 \\
\hline & Change & -0.041 & 0.053 & 0.199 & 0.205 & 0.049 \\
\hline \multirow[t]{3}{*}{ LDL cholesterol (mg/dL) } & September & 0.129 & 0.014 & -0.055 & -0.001 & 0.089 \\
\hline & January & 0.089 & 0.065 & -0.045 & 0.071 & 0.081 \\
\hline & Change & -0.075 & 0.089 & 0.020 & 0.126 & -0.016 \\
\hline \multirow[t]{3}{*}{ Apo-lipoprotein $\mathrm{A}_{1}(\mathrm{mg} / \mathrm{dL})$} & September & -0.060 & -0.035 & -0.150 & -0.135 & -0.117 \\
\hline & January & -0.051 & -0.029 & -0.083 & -0.079 & -0.056 \\
\hline & Change & 0.023 & 0.014 & 0.133 & 0.111 & 0.119 \\
\hline \multirow[t]{3}{*}{ Apo-lipoprotein B (mg/dL) } & September & 0.141 & 0.005 & -0.006 & -0.001 & 0.141 \\
\hline & January & 0.094 & 0.076 & -0.004 & 0.075 & 0.101 \\
\hline & Change & -0.101 & 0.136 & 0.004 & 0.145 & -0.087 \\
\hline
\end{tabular}

Significance value; ${ }^{*} p<0.05$.

eating of Satsuma mandarin while it is in season may influence lipid metabolism throughout the year. To clarify whether Satsuma mandarin consumption improves lipid metabolism, an intervention study is needed.

On the other hand, many studies have examined the content of lipid-soluble antioxidants, such as carotenoids and tocopherol in lipoprotein (14-17). These lipid-soluble antioxidants are carried by LDL from liver into blood circulation. In comparison with $\beta$-carotene, polar xanthophylls, such as $\beta$-CRX or zeaxanthin, are 
distributed equally between LDL and HDL (15). However, these relationships between serum carotenoid and lipoprotein have been discussed in studies in which the carotenoid levels found were much lower than those in our study. In our cross-sectional analyses, LDL-cholesterol was positively correlated with serum $\beta$-CRX concentration in September, but no positive correlation was observed in January (Table 2). In contrast, serum HDLcholesterol was not correlated with serum $\beta$-CRX in September, but statistically positive correlation was observed in January (Table 2). These results suggest that $\beta$-CRX is mainly transported by HDL rather than LDL when the serum $\beta$-CRX level increases to an extreme degree. Whether the distribution of carotenoids in lipoprotein is dependent upon the serum concentration of carotenoids remains unclear. The relationship between lipoprotein and carotenoids when the serum concentration of carotenoid is as high as $\beta$-CRX in our study has never before been reported. We are now examining the content of $\beta$-CRX in each lipoprotein.

Many reports have shown the beneficial effects of consuming fruits and vegetables on lipid metabolism $(18-21)$, and this beneficial effect of fruits and vegetables is connected with the prevention of cardiovascular diseases. The serum lipid-ameliorating effects of consuming fruits and vegetable are attributed to the effects of bioactive substances, such as dietary fiber and flavonoids. Satsuma mandarin is a well-known source of these compounds. Among fruits and vegetables, Satsuma mandarin is a popular source of hesperidin in Japan (22). Hesperidin has been reported to have an inhibitory effect on cholesterol biosynthesis (20). To clarify whether Satsuma mandarin consumption influence lipid metabolism, further studies are needed.

\section{Acknowledgments}

This study was supported in part by a grant from the Ministry of Agriculture, Forestry, and Fishers (MAFF) for a food research project titled "Integrated Research on Safety and Physiological Function of Food" and with special coordination funds from the Ministry of Education, Culture, Sports, Science and Technology, Japan. The authors thank all of the participants who volunteered for the study. The authors also thank Mrs. H. Horiike, Mrs. A. Kawasaki, and Ms. Y. Fukazawa for technical assistance in the analysis of the blood samples and the dietary data.

\section{REFERENCES}

1) Jenkins DJ, Popovich DG, Kendall CW, Vidgen E, Tariq N, Ransom TP, Wolever TM, Vuksan V, Mehling CC, Boctor DL, Bolognesi C, Huang J, Patten R. 1997. Effect of a diet high in vegetables, fruit, and nuts on serum lipids. Metabolism 46: 530-537.

2) Feldman EB. 2001. Fruits and vegetables and risk of stroke. Nutr Rev 59: 24-27.

3) Ford ES, Mokdad AH. 2001. Fruit and vegetable consumption and diabetes mellitus incidence among U.S. adults. Prev Med 32: 33-39.

4) Hooper L. 2001. Dietetic guidelines: diet in secondary prevention of cardiovascular disease. J Hum Nutr Diet 14: 297-305.

5) Terry P, Terry JB, Wolk A. 2001. Fruit and vegetable consumption in the prevention of cancer: an update. $J$ Intern Med 250: 280-290.

6) Sugiura M, Kato M, Matsumoto H, Nagao A, Yano M. 2002. Serum concentration of $\beta$-cryptoxanthin in Japan reflects the frequency of Satsuma mandarin (Citrus unshiu Marc.) consumption. J Health Sci 48: 350353.

7) Sugiura M, Matsumoto H, Kato M, Ikoma Y, Yano M, Nagao A. 2004. Multiple linear regression analysis of the seasonal changes in the serum concentration of $\beta$ cryptoxanthin. J Nutr Sci Vitaminol 50: 196-202.

8) Mangels AR, Holden JM, Beecher GR, Forman MR, Lanza E. 1993. Carotenoid content of fruits and vegetables: an evaluation of analytic data. J Am Diet Assoc 93: 284-296.

9) Holden JM, Eldrige AL, Beecher GR, Buzzard MI, Bhagwat S, Davis CS, Douglass LW, Gebhardt S, Haytowitz D, Schakel S. 1999. Carotenoid content of U.S. foods: an update of the database. J Food Comp Anal 12: 169-196.

10) Breithaupt DE, Bamedi A. 2001. Carotenoid esters in vegetables and fruits: a screening with emphasis on $\beta$ cryptoxanthin esters. J Agric Food Chem 49: 2064 2070.

11) Goodner KL, Rouseff RL, Hofsommer HJ. 2001. Orange, mandarin, and hybrid classification using multivariate statistics based on carotenoid profiles. J Agric Food Chem 49: 1146-1150.

12) Michaud DS, Giovannucci EL, Ascherio A, Rimm EB, Forman MR, Sampson L, Willett WC. 1998. Associations of plasma carotenoid concentrations and dietary intake of specific carotenoids in samples of two prospective cohort studies using a new carotenoid database. Cancer Epidemiol Biomarker Prev 7: 283-290.

13) Ford ES. 2000. Variations in serum carotenoid concentrations among United States adults by ethnicity and sex. Ethn Dis 10: 208-217.

14) Ribaya-Mercado JD, Ordovas JM, Russell RM. 1995. Effect of beta-carotene supplementation on the concentration and distribution of carotenoids, vitamin E, vitamin A, and cholesterol in plasma lipoprotein and nonlipoprotein fractions healthy older women. J Am Coll Nutr 14: 614-620.

15) Romanchik JE, Morel DW, Harrison EH. 1995. Distributions of carotenoids and alpha-tocopherol among lipoproteins do not change when human plasma is incubated in vitro. J Nutr 125:2610-2617.

16) Ziouzenkova O, Winklhofer-Roob BM, Puhl H, Roob JM, Esterbauer H. 1996. Lack of correlation between the $\alpha$ tocopherol content of plasma and LDL, but high correlations for $\gamma$-tocopherol and carotenoids. J Lipid Res 37 : 1936-1946.

17) Goulinet S, Chapman MJ. 1997. Plasma LDL and HDL subspecies are heterogenous in particle content of tocopherols and oxygenated and hydrocarbon carotenoids relevance to oxidative resistance and atherogenesis. Arterioscler Tromb Vasc Biol 17: 786-796.

18) Cerda JJ, Robbins FL, Burgin CW, Baumgartner TG, Rice RW. 1988. The effects of grapefruit pectin on patients at risk for coronary heart disease without altering diet or lifestyle. Clin Cardiol 11: 589-594.

19) Jenkins DJ, Popovich DG, Kendall CW, Vidgen E, Tariq N, Ransom TP, Wolever TM, Vuksan V, Mehling CC, Boctor 
DL, Bolognesi C, Huang J, Patten R. 1997. Effect of a diet high in vegetables, fruit, and nuts on serum lipids. Metabolism 46: 530-537.

20) Bok SH, Lee SH, Park YB, Bae KH, Son KH, Jeong TS, Choi MS. 1999. Plasma and hepatic cholesterol and hepatic activities of 3-hydroxy-3-methyl-glutaryl-CoA reductase and acyl CoA: cholesterol transferase are lower in rats fed citrus peel extract or a mixture of citrus bioflavonoids. J Nutr 129: 1182-1185.

21) Kurowska EM, Spence JD, Jordan J, Wetmore S, Freeman DJ, Piche LA, Serratore P. 2000. HDL-cholesterol-raising effect of orange juice in subjects with hypercholesterolemia. Am J Clin Nutr 72: 1095-1100.

22) Kawaii S, Tomono Y, Katase E, Ogawa K, Yano M. 1999. Quantitation of flavonoid constituents in citrus fruis. J Agric Food Chem 47: 3565-3571. 